Supplement of Biogeosciences, 17, 6081-6095, 2020 https://doi.org/10.5194/bg-17-6081-2020-supplement (C) Author(s) 2020. This work is distributed under the Creative Commons Attribution 4.0 License.

(c) (1)

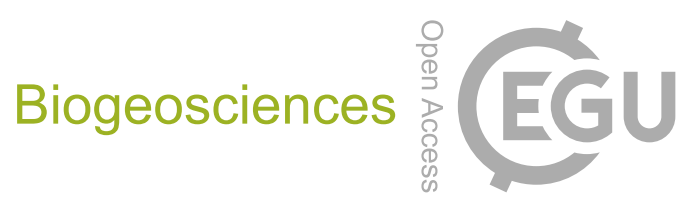

Supplement of

\title{
Microbial functional signature in the atmospheric boundary layer
}

Romie Tignat-Perrier et al.

Correspondence to: Romie Tignat-Perrier (romie.tignat-perrier@univ-grenobe-alpes.fr)

The copyright of individual parts of the supplement might differ from the CC BY 4.0 License. 


\section{Microbial functional signature in the atmospheric boundary layer}

Romie Tignat-Perrier ${ }^{1,2}$, Aurélien Dommergue ${ }^{1}$, Alban Thollot $^{1}$, Olivier Magand ${ }^{1}$, Timothy M. Vogel ${ }^{2}$,

Catherine Larose ${ }^{2}$

${ }^{1}$ Institut des Géosciences de l'Environnement, Université Grenoble Alpes, CNRS, IRD, Grenoble INP, Grenoble, France

${ }^{2}$ Environmental Microbial Genomics, Laboratoire Ampère, École Centrale de Lyon, Université de Lyon, Écully, France

Correspondence to: Romie Tignat-Perrier (romie.tignat-perrier@univ-grenobe-alpes.fr)

\section{Supplementary Materials}

\section{Supplementary Figures}

Fig S1. Surrounding landscapes of the air sampling sites.

Fig S2. Distribution of the samples based on the microbial functional profile when considering all, bacterial or fungal sequences.

Fig S3. Proportion of sequences annotated as hydrogen peroxide catabolic process related functional proteins as well as proteins potentially implicated in stress resistance in the metagenomes.

Fig S4. Proportion of sequences annotated as UV protection and desiccation response related functional proteins in the metagenomes.

3 Supplementary tables

Table S1. Air sample collection characteristics.

Table S2. Characteristics of the metagenomes.

Table S3. Functional richness and evenness averaged per site.

Table S4. Ratio between fungal and bacterial cell concentration in air and soil.

Table S5. Dominant SEED functions in the metagenomes. 


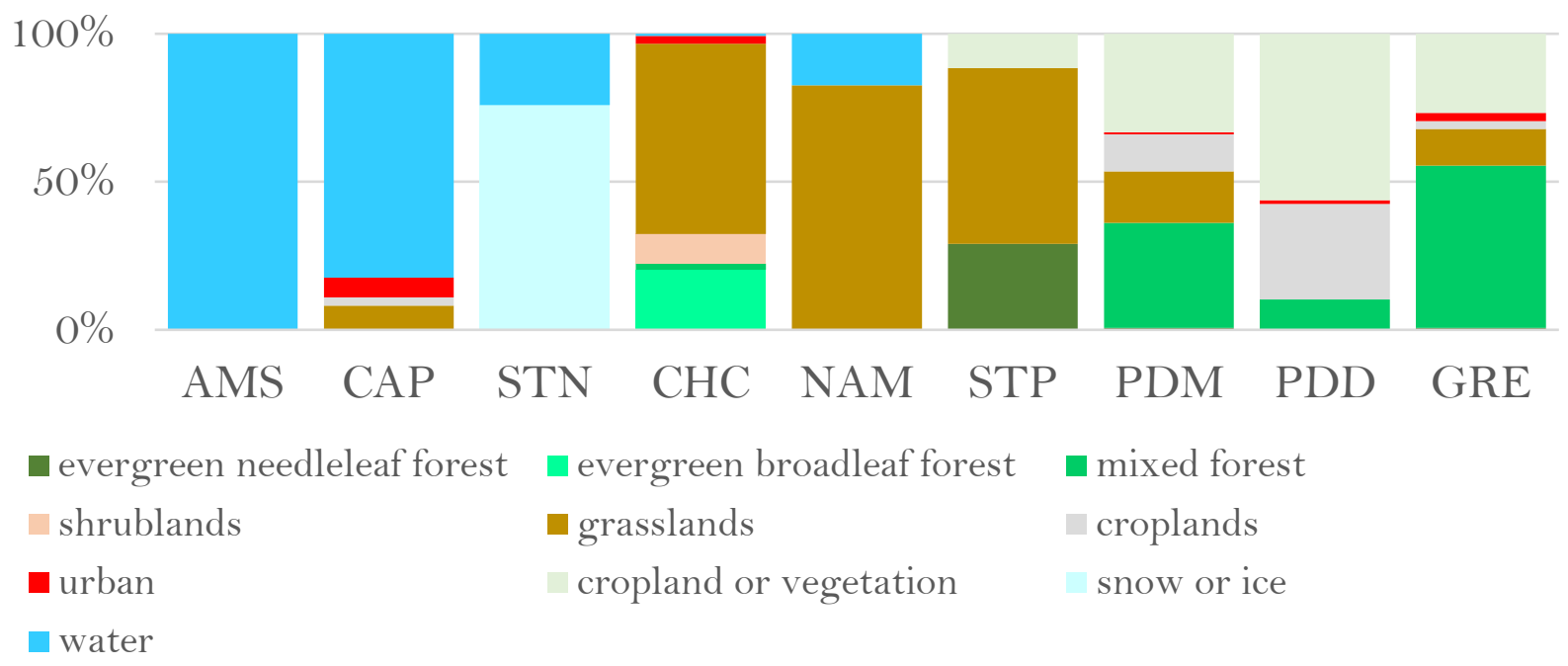

Fig S1. Surrounding landscapes of the air sampling sites. The proportions of different landscapes within a perimeter of $50 \mathrm{~km}$ have been calculated based on the land cover MODIS approach. AMS: Amsterdam-Island, CAP: Cape-Point, STN: Station Nord, CHC: Chacaltaya, NAM: Namco, STP: Storm Peak, PDM: Pic-du-Midi, PDD: puy de Dôme, GRE: Grenoble. 


\section{Supplementary Figures}
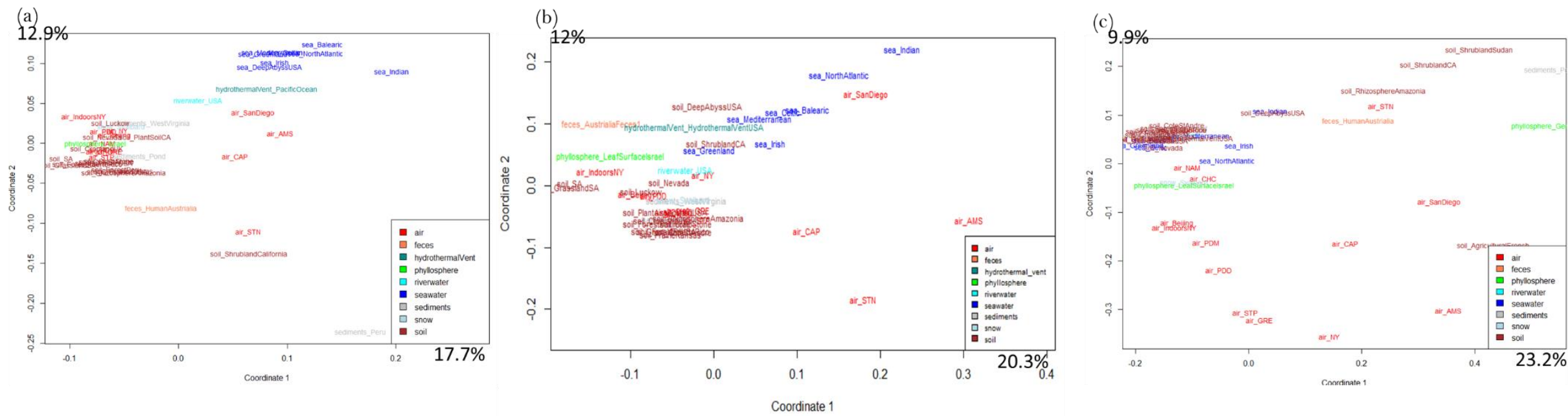

Fig S2. Distribution of the samples based on the microbial functional profile when considering all, bacterial or fungal sequences. PCoA analysis of the

Bray-Curtis dissimilarity matrix based on the functional potential structure of each site. All sequences (a), bacterial sequences (b) and fungal sequences (c) have been used for functional annotation. For the site including several metagenomes, the average profile was calculated. Colors indicate the ecosystems in which the sites belong to. 


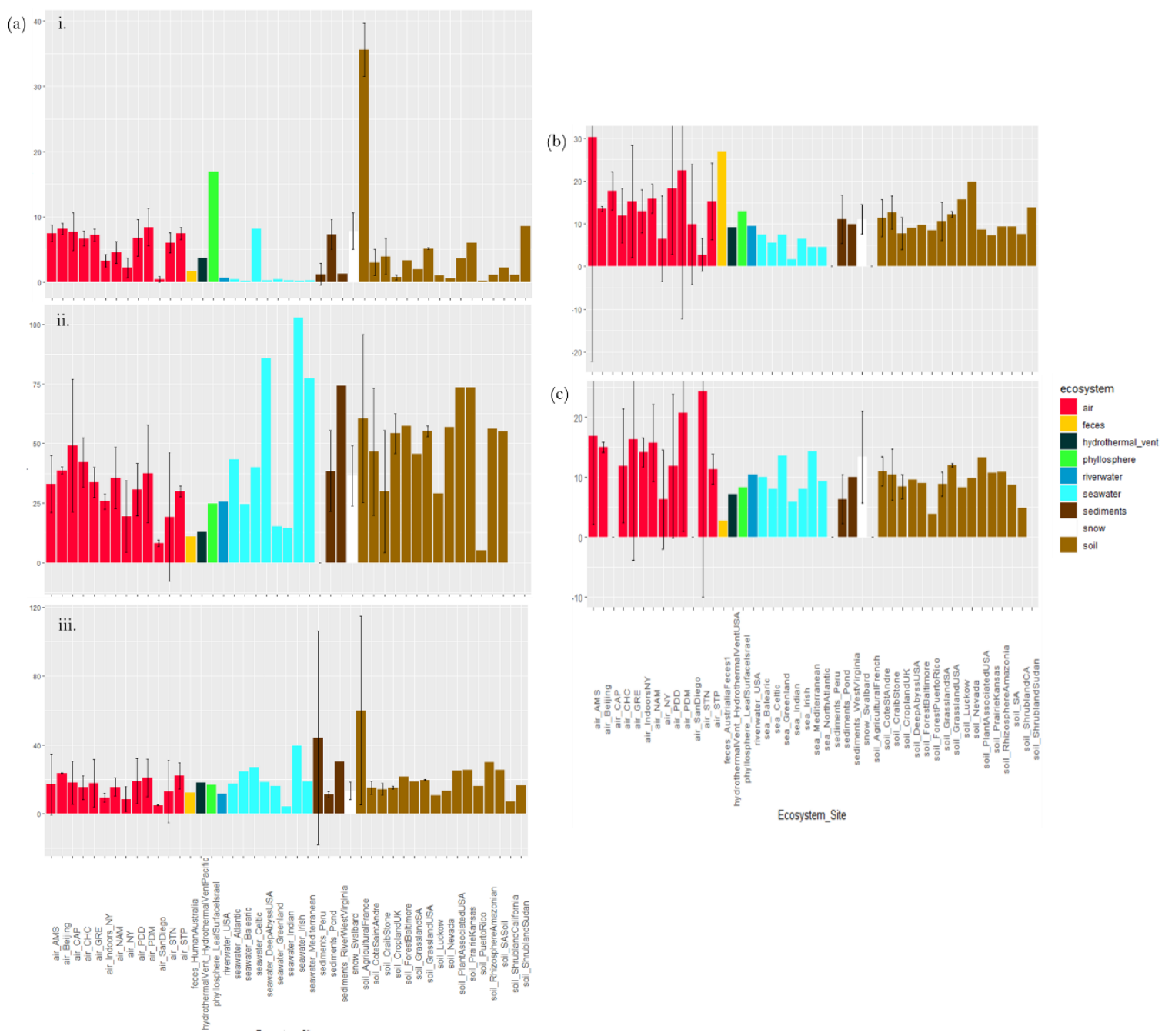

Fig S3. Proportion of sequences annotated as hydrogen peroxide catabolic process related functional proteins as well as proteins potentially implicated in stress resistance in the metagenomes. Average number of sequences annotated as proteins implicated in the hydrogen peroxide catabolic process (a, left) per 10000 annotated sequences from (i) all sequences, (ii) fungal sequences and (iii) bacterial sequences per site, and average number of hits of lipoate synthase (b) and chromosome plasmid partitioning protein ParA (c) per 10000 annotated sequences from all sequences per site. Colors indicate the ecosystems in which the sites belong to. For the sites including several metagenomes, the standard deviation was added. 

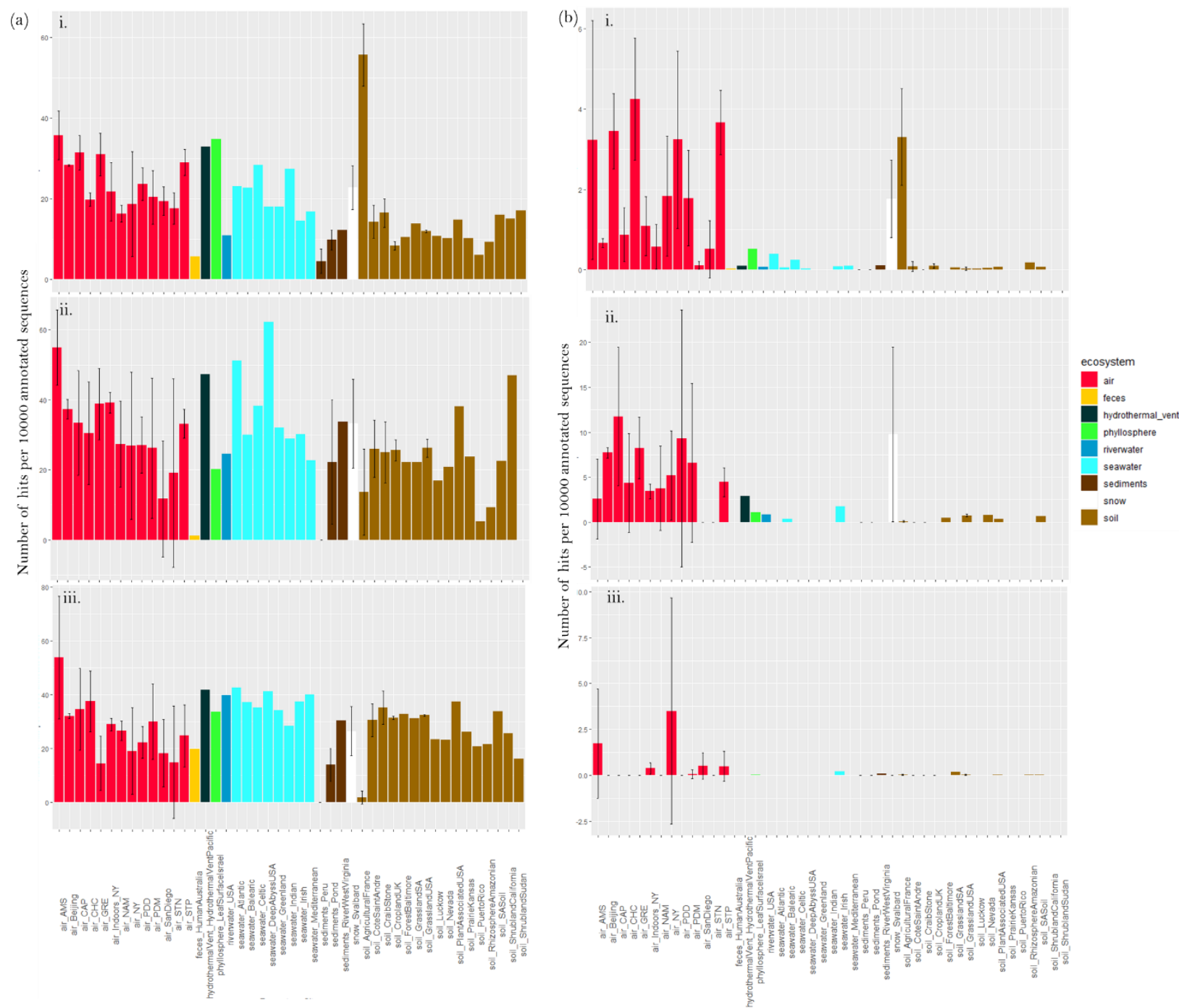

Fig S4. Proportion of sequences annotated as UV protection and desiccation response related functional proteins in the metagenomes. Average number of sequences annotated as proteins implicated in the UV protection (a, left) and desiccation response (b, right) per 10000 annotated sequences from (i) all sequences, (ii) fungal sequences and (iii) bacterial sequences per site. Colors indicate the ecosystems in which the sites belong to. For the sites including several metagenomes, the standard deviation was added. 


\section{Supplementary tables}

Table S1. Air sample collection characteristics. Standardized collected air volume and sampling starting date of each air sample that we collected for this study. AMS: Amsterdam Island, CAP: Cape Point, CHC: Chacaltaya, GRE: Grenoble, NAM: Namco, PDD: Puy de Dôme, PDM: Pic du Midi, STN: Station Nord, STP: Storm Peak

\begin{tabular}{|c|c|c|c|c|}
\hline \multirow{3}{*}{ Site } & \multicolumn{3}{|c|}{ Standardized } & \multirow{3}{*}{$\begin{array}{l}\text { Sampling starting date } \\
\text { (ending date: exactly } 7 \text { days } \\
\text { after) (month/day/year) }\end{array}$} \\
\hline & Sample name & collected air & High volume air sampler & \\
\hline & & volume $\left(\mathrm{m}^{3}\right)$ & & \\
\hline$\overline{\mathrm{AMS}}$ & AMS_10/09/2016 & 5232 & Digitel PM10 head + pump & $10 / 09 / 16$ \\
\hline AMS & AMS_08/10/2016 & 4449 & Digitel PM10 head + pump & $08 / 10 / 16$ \\
\hline AMS & AMS_21/10/2016 & 5059 & Digitel PM10 head + pump & $10 / 21 / 16$ \\
\hline CAP & CAP_21/10/2016 & 4679 & Digitel DA77 sampler & $10 / 21 / 16$ \\
\hline CAP & CAP_28/10/2016 & 545 & Digitel DA77 sampler & $10 / 28 / 16$ \\
\hline $\mathrm{CHC}$ & CHC_23/09/2016 & 1148 & Digitel PM10 head + pump & $09 / 23 / 16$ \\
\hline $\mathrm{CHC}$ & CHC_21/10/2016 & 1154 & Digitel PM10 head + pump & $10 / 21 / 16$ \\
\hline $\mathrm{CHC}$ & CHC_28/10/2016 & 1220 & Digitel PM10 head + pump & $10 / 28 / 16$ \\
\hline $\mathrm{CHC}$ & CHC_01/07/2016 & 1284 & Digitel PM10 head + pump & $01 / 07 / 16$ \\
\hline $\mathrm{CHC}$ & CHC_08/07/2016 & 1284 & Digitel PM10 head + pump & $08 / 07 / 16$ \\
\hline $\mathrm{CHC}$ & CHC_15/07/2016 & 1289 & Digitel PM10 head + pump & $07 / 15 / 16$ \\
\hline $\mathrm{CHC}$ & CHC_12/08/2016 & 1160 & Digitel PM10 head + pump & $12 / 08 / 16$ \\
\hline $\mathrm{CHC}$ & CHC_19/08/2016 & 1158 & Digitel PM10 head + pump & $08 / 19 / 16$ \\
\hline $\mathrm{CHC}$ & CHC_O2/09/2016 & 1156 & Digitel PM10 head + pump & $02 / 09 / 16$ \\
\hline GRE & GRE_03/07/2017 & 4688 & Digitel PM10 head + pump & $03 / 07 / 17$ \\
\hline GRE & GRE_10/07/2017 & 4717 & Digitel PM10 head + pump & $10 / 07 / 17$ \\
\hline GRE & GRE_17/07/2017 & 4677 & Digitel PM10 head + pump & $07 / 17 / 17$ \\
\hline GRE & GRE_24/07/2017 & 4718 & Digitel PM10 head + pump & $07 / 24 / 17$ \\
\hline GRE & GRE_31/07/2017 & 4665 & Digitel PM10 head + pump & $07 / 31 / 17$ \\
\hline GRE & GRE_07/08/2017 & 4762 & Digitel PM10 head + pump & $07 / 08 / 17$ \\
\hline GRE & GRE_14/08/2017 & 4729 & Digitel PM10 head + pump & $08 / 14 / 17$ \\
\hline GRE & GRE_21/08/2017 & 4707 & Digitel PM10 head + pump & $08 / 21 / 17$ \\
\hline GRE & GRE_04/09/2017 & 4742 & Digitel PM10 head + pump & $04 / 09 / 17$ \\
\hline NAM & NAM_17/05/2017 & 5511 & 2131 Laowin chinese sampler & $05 / 17 / 17$ \\
\hline NAM & NAM_25/05/2017 & 5503 & 2131 Laowin chinese sampler & $05 / 25 / 17$ \\
\hline NAM & NAM_02/06/2017 & 5513 & 2131 Laowin chinese sampler & $02 / 06 / 17$ \\
\hline NAM & NAM_13/06/2017 & 4218 & 2131 Laowin chinese sampler & $06 / 13 / 17$ \\
\hline NAM & NAM_20/06/2017 & 5418 & 2131 Laowin chinese sampler & $06 / 20 / 17$ \\
\hline
\end{tabular}




\begin{tabular}{|c|c|c|c|c|}
\hline NAM & NAM_29/06/2017 & 5415 & 2131 Laowin chinese sampler & $06 / 29 / 17$ \\
\hline NAM & NAM_07/07/2017 & 5483 & 2131 Laowin chinese sampler & $07 / 07 / 17$ \\
\hline NAM & NAM_14/07/2017 & 5413 & 2131 Laowin chinese sampler & $07 / 14 / 17$ \\
\hline NAM & NAM_21/07/2017 & 5465 & 2131 Laowin chinese sampler & $07 / 21 / 17$ \\
\hline PDD & PDD_07/06/2017 & 8761 & Digitel PM10 head + pump & $06 / 07 / 17$ \\
\hline PDD & PDD_14/06/2017 & 8360 & Digitel PM10 head + pump & $06 / 14 / 17$ \\
\hline PDD & PDD_21/06/2017 & 8672 & Digitel PM10 head + pump & $06 / 21 / 17$ \\
\hline PDD & PDD_28/06/2017 & 9012 & Digitel PM10 head + pump & $06 / 28 / 17$ \\
\hline PDD & PDD_02/08/2017 & 7399 & Digitel PM10 head + pump & $08 / 02 / 17$ \\
\hline PDD & PDD_09/08/2017 & 9926 & Digitel PM10 head + pump & $08 / 09 / 17$ \\
\hline PDD & PDD_30/05/2017 & 10232 & Digitel PM10 head + pump & $05 / 30 / 17$ \\
\hline PDD & PDD_12/07/2017 & 8713 & Digitel PM10 head + pump & $07 / 12 / 17$ \\
\hline PDD & PDD_19/07/2017 & 8620 & Digitel PM10 head + pump & $07 / 19 / 17$ \\
\hline PDD & PDD_26/07/2017 & 8664 & Digitel PM10 head + pump & $07 / 26 / 17$ \\
\hline PDM & PDM_20/06/2016 & 9664 & TISCH TE-5170V sampler & $06 / 20 / 16$ \\
\hline PDM & PDM_29/06/2016 & 6803 & TISCH TE-5170V sampler & $06 / 29 / 16$ \\
\hline PDM & PDM_12/07/2016 & 7550 & TISCH TE-5170V sampler & $12 / 07 / 16$ \\
\hline PDM & PDM_19/07/2016 & 8040 & TISCH TE-5170V sampler & $07 / 19 / 16$ \\
\hline PDM & PDM_26/07/2016 & 7794 & TISCH TE-5170V sampler & $07 / 26 / 16$ \\
\hline PDM & PDM_02/08/2016 & 8103 & TISCH TE-5170V sampler & $02 / 08 / 16$ \\
\hline PDM & PDM_09/08/2016 & 7747 & TISCH TE-5170V sampler & $08 / 09 / 16$ \\
\hline PDM & PDM_16/08/2016 & 8100 & TISCH TE-5170V sampler & $08 / 16 / 16$ \\
\hline PDM & PDM_23/08/2016 & 7956 & TISCH TE-5170V sampler & $08 / 23 / 16$ \\
\hline PDM & PDM_13/09/2016 & 7931 & TISCH TE-5170V sampler & $09 / 13 / 16$ \\
\hline PDM & PDM_20/09/2016 & 7853 & TISCH TE-5170V sampler & $09 / 20 / 16$ \\
\hline PDM & PDM_06/09/2016 & 7867 & TISCH TE-5170V sampler & $06 / 09 / 16$ \\
\hline PDM & PDM_16/08/2016 & 8100 & TISCH TE-5170V sampler & $08 / 16 / 16$ \\
\hline STN & STN_27/03/2017 & 5153 & Digitel DA80 sampler & $03 / 27 / 17$ \\
\hline STN & STN_15/05/2017 & 5246 & Digitel DA80 sampler & $05 / 15 / 17$ \\
\hline STP & STP_14/07/2017 & 11213 & TISCH PM10 sampler & $07 / 14 / 17$ \\
\hline STP & STP_21/07/2017 & 9333 & TISCH PM10 sampler & $07 / 21 / 17$ \\
\hline STP & STP_28/07/2017 & 5702 & TISCH PM1O sampler & $07 / 28 / 17$ \\
\hline STP & STP_11/08/2017 & 5702 & TISCH PM10 sampler & $08 / 11 / 17$ \\
\hline STP & STP_18/08/2017 & 5702 & TISCH PM10 sampler & $08 / 18 / 17$ \\
\hline STP & STP_25/08/2017 & 5702 & TISCH PM10 sampler & $08 / 25 / 17$ \\
\hline
\end{tabular}


Table S2. Characteristics of the metagenomes. Number of samples, ecosystem, sequencing technology, database and accession number, number of sequences per sample (mean + standard deviation), percentage of fungal and bacterial sequences per site and percentage of annotated sequences (mean + standard deviation) per site.

\begin{tabular}{|c|c|c|c|c|c|c|c|c|c|c|c|c|c|c|c|c|}
\hline & & & & & & & & & & & Percentage o & & & & & \\
\hline Site & $\begin{array}{l}\text { Country/ } \\
\text { Ocean }\end{array}$ & $\begin{array}{l}\text { Information on } \\
\text { the site }\end{array}$ & $\begin{array}{l}\text { Number } \\
\text { of } \\
\text { samples }\end{array}$ & Ecosystem & $\begin{array}{l}\text { Sequencing } \\
\text { technology }\end{array}$ & $\begin{array}{l}\text { Database and } \\
\text { reference numbers or } \\
\text { study }\end{array}$ & $\begin{array}{l}\text { Total sequence } \\
\text { number }\end{array}$ & $\begin{array}{l}\text { Annotated } \\
\text { sequence } \\
\text { number by } \\
\text { eggNOG- } \\
\text { Mapper }\end{array}$ & $\begin{array}{l}\text { Fungi- } \\
\text { associated } \\
\text { sequences }\end{array}$ & $\begin{array}{l}\text { Percentage of } \\
\text { fungi- } \\
\text { associated } \\
\text { sequences } \\
\text { over total read } \\
\text { number }\end{array}$ & $\begin{array}{l}\text { fungi- } \\
\text { associated } \\
\text { sequences } \\
\text { over fungi-an } \\
\text { bacteria- } \\
\text { associated } \\
\text { sequence } \\
\text { number }\end{array}$ & $\begin{array}{l}\text { Percentage of } \\
\text { fungi- } \\
\text { associated } \\
\text { dsequences } \\
\text { annotated by } \\
\text { eggNOG- } \\
\text { Mapper }\end{array}$ & $\begin{array}{l}\text { Bacteria- } \\
\text { associated } \\
\text { sequence } \\
\text { number }\end{array}$ & $\begin{array}{l}\text { Percentage of } \\
\text { bacteria- } \\
\text { associated } \\
\text { sequences } \\
\text { over total } \\
\text { sequence } \\
\text { number }\end{array}$ & $\begin{array}{l}\text { Percentage of } \\
\text { bacteria-associated } \\
\text { sequences over } \\
\text { fungi-and bacteria- } \\
\text { associated sequence } \\
\text { number }\end{array}$ & $\begin{array}{l}\text { Percentage of } \\
\text { bacteria-associated } \\
\text { sequences } \\
\text { annotated by } \\
\text { eggNOG- Mapper }\end{array}$ \\
\hline $\begin{array}{l}\text { Air Amsterdam-Island } \\
\text { (AMS) }\end{array}$ & $\begin{array}{l}\text { Sub- } \\
\text { Antarctica }\end{array}$ & marine, remote & 3 & air & Miseq & present study & $97881+-93551$ & $17676+-15995$ & $4152+-4089$ & $4.1+-0.2$ & $71+-4$ & $60+-2$ & $1670+-1549$ & $1.7+-0.4$ & $29+-4$ & $57+-2$ \\
\hline Air Beijing & China & urban & 2 & air & HiSeq & $\begin{array}{l}\operatorname{mgm} 4516366.3, \\
\operatorname{mgm} 4516459.3\end{array}$ & $2248590+-177298$ & $141849+-9576$ & $250843+-91619$ & $911+-3.2$ & $52+-10$ & $17+-1$ & $226290+-8208$ & $10.1+-1.2$ & $48+-10$ & $39+-1$ \\
\hline Air Cape-Point (CAP) & South-Africa & coastal & 2 & air & Miseq & present study & $90043+-6341$ & $20479+-1447$ & $7227+-5972$ & $7.8+-6.1$ & $56+-29$ & $50+-12$ & $4530+-1286$ & $5.1+-1.8$ & $44+-29$ & $61+-1$ \\
\hline Air Chacaltaya $(\mathrm{CHC})$ & Bolivia & $\begin{array}{l}\text { high-altitude } \\
\text { mountain peak }\end{array}$ & 9 & air & MiSeq & present study & $103239+-54187$ & $32699+-18131$ & $3479+-2580$ & $3.5+-1.2$ & $27+-24$ & $61+-7$ & $11113+-6411$ & $10.2+-2$ & $73+-24$ & $67+-2$ \\
\hline Air Grenoble (GRE) & France & urban & 9 & air & Miseq & $\begin{array}{l}\text { present study } \\
\text { SRR 1000232, }\end{array}$ & $248064+-158109$ & $42853+-30690$ & $24234+-15561$ & $9.7+-0.5$ & $79+-10$ & $48+-3$ & $7082+-8061$ & $2.7+-1.6$ & $21+-10$ & $59+-5$ \\
\hline $\begin{array}{l}\text { Air New York indoors } \\
\text { (indoors_NY) }\end{array}$ & USA & indoors & 4 & air & 454 & $\begin{array}{l}\text { SRR 1000254, } \\
\text { SRR999213, } \\
\text { SRR999215 }\end{array}$ & $400997+-49680$ & $126245+-12742$ & $236858+-16604$ & $9.2+-4.1$ & $52+-17$ & $47+-8$ & $32035+-10923$ & $8.3+-3.7$ & $48+-17$ & $70+-9$ \\
\hline Air Namco (NAM) & China & $\begin{array}{l}\text { high-altitude plateau, } \\
\text { semi-arid }\end{array}$ & 9 & air & MiSeq & present study & $149952+-92976$ & $48012+-36340$ & $2958+-1910$ & $2.1+-1.1$ & $19+-12$ & $68+-9$ & $15901+-13188$ & $10+-2.6$ & $81+-12$ & $69+-2$ \\
\hline Air New York (NY) & USA & urban, coastal & 6 & air & 454 & $\begin{array}{l}\text { SRR1000260, } \\
\text { SRR1000269, } \\
\text { SRR999217, } \\
\text { SRR999218, } \\
\text { SRR999219, } \\
\text { SRR999220 }\end{array}$ & $521791+-277049$ & $99566+-51023$ & $85350+-41529$ & $20+-11.6$ & $56+-8$ & $46+-41$ & $69161+-38301$ & $18.1+-14.5$ & $44+-8$ & $37+-47$ \\
\hline $\begin{array}{l}\text { Air Puy-de-Dôme } \\
\text { (PDD) }\end{array}$ & France & $\begin{array}{l}\text { continental, moutain } \\
\text { peak }\end{array}$ & 10 & air & MiSeq & present study & $396666+-364681$ & $65304+-68592$ & $25029+-32432$ & $5.8+-2.5$ & $62+-16$ & $50+-6$ & $13112+-12079$ & $3.9+-3$ & $38+-16$ & $56+-4$ \\
\hline
\end{tabular}




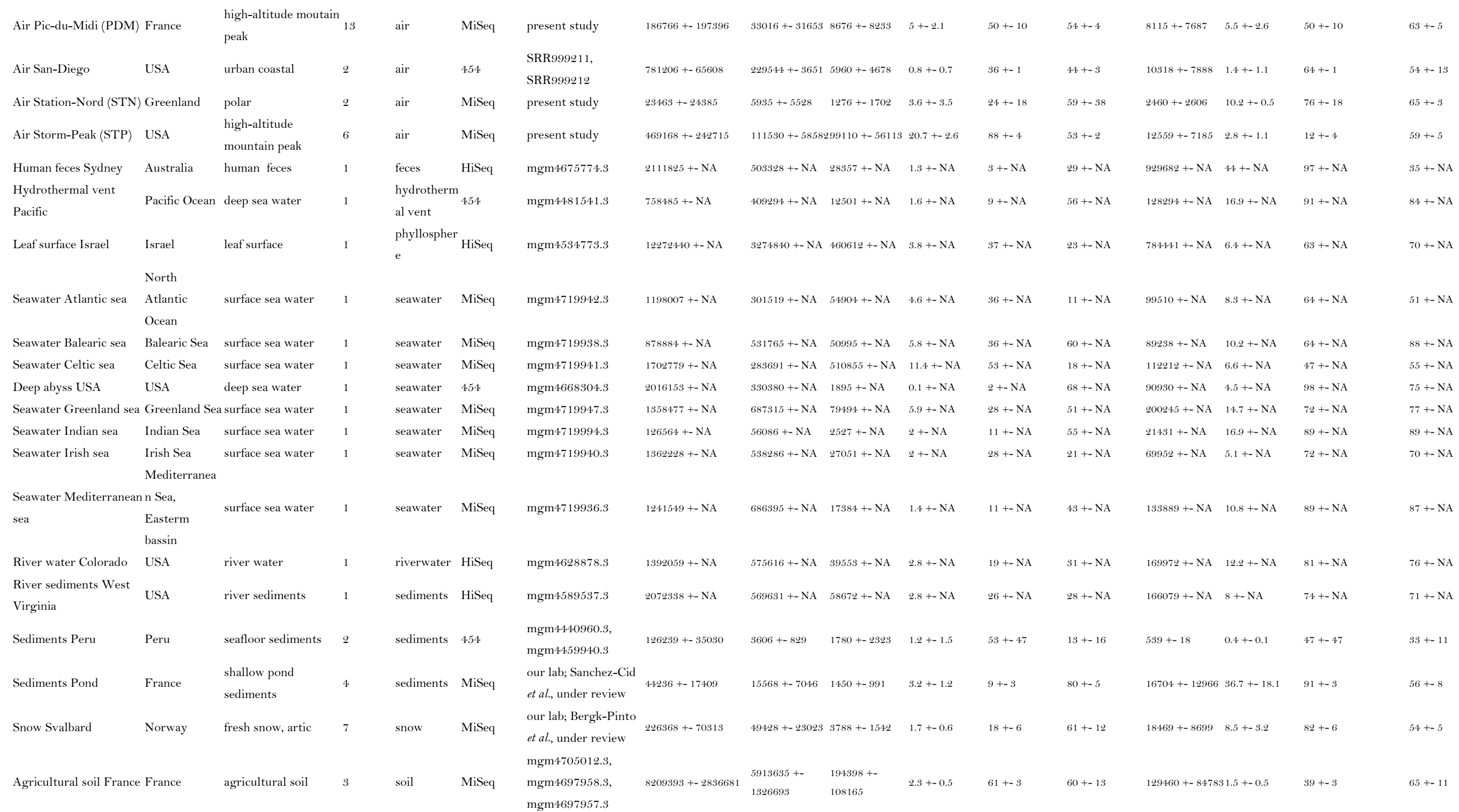




\begin{tabular}{|c|c|c|c|c|c|c|c|c|c|c|c|c|c|c|c|c|}
\hline Soil Cote Saint Andre & France & agricultural soil & 6 & soil & MiSeq & $\begin{array}{l}\text { our lab; Sanchez-Cid } \\
\text { et al., under review }\end{array}$ & $174898+-80968$ & $54841+-22225$ & $1638+-640$ & $1+-0.1$ & $9+-1$ & $82+-2$ & $16806+-6846$ & $9.8+-0.6$ & $91+-1$ & $67+-1$ \\
\hline Soil CraibStone & Scottland & agricultural soil & 5 & soil & MiSeq & $\begin{array}{l}\text { our lab; Sanchez-Cid } \\
\text { et al, under review }\end{array}$ & $128815+-82837$ & $41175+-22413$ & $1452+-953$ & $1.1+-0.1$ & $9+-1$ & $78+-4$ & $15472+-11906$ & $11.5+-1.2$ & $91+-1$ & $65+-1$ \\
\hline Cropland UK & $\begin{array}{l}\text { United } \\
\text { Kingdom }\end{array}$ & cropland & 2 & soil & MiSeq & $\begin{array}{l}\operatorname{mgm} 4781436.3, \\
\operatorname{mgm} 4781437.3\end{array}$ & $485163+-163475$ & $\begin{array}{l}304642+- \\
104503\end{array}$ & $9970+-3861$ & $2+-0.1$ & $13+-0$ & $88+-\mathrm{NA}$ & $66040+-25119$ & $13.5+-0.6$ & $87+-0$ & $95+-0$ \\
\hline Forest soil Baltimore & USA & $\begin{array}{l}\text { temperate deciduous } \\
\text { broadleaf forest soil }\end{array}$ & 1 & soil & Miseq & $\operatorname{mgm} 4819073.3$ & $4600481+-\mathrm{NA}$ & $959764+-\mathrm{NA}$ & $34207+-\mathrm{NA}$ & $0.7+-\mathrm{NA}$ & $12+-\mathrm{NA}$ & $62+-\mathrm{NA}$ & $260826+-\mathrm{NA}$ & $5.7+-\mathrm{NA}$ & $88+-\mathrm{NA}$ & $79+-\mathrm{NA}$ \\
\hline Grassland USA & South-Africa & tropical grassland & 1 & soil & MiSeq & $\operatorname{mgm} 4819072.3$ & $2519738+-\mathrm{NA}$ & $638149+-\mathrm{NA}$ & $22974+-\mathrm{NA}$ & $0.9+-\mathrm{NA}$ & $8+-\mathrm{NA}$ & $63+-\mathrm{NA}$ & $279551+-\mathrm{NA}$ & $11.1+-\mathrm{NA}$ & $92+-\mathrm{NA}$ & $79+-\mathrm{NA}$ \\
\hline Grassland USA & USA & temperate grassland & 2 & soil & Miseq & $\begin{array}{l}\text { mgm4623641.3, } \\
\text { mgm4623640.3 }\end{array}$ & $12195227+-1436683$ & $\begin{array}{l}697967+- \\
122932\end{array}$ & $1753640+-1903$ & $314.5+-1.7$ & $42+-1$ & $2+-0$ & $\begin{array}{l}2381163+- \\
99911\end{array}$ & $19.6+-1.5$ & $58+-1$ & $13+-2$ \\
\hline Soil Lucknow India & India & soil & 1 & soil & 454 & $\operatorname{mgm} 4461840.3$ & $1187505+-\mathrm{NA}$ & $658023+-\mathrm{NA}$ & $53911+-\mathrm{NA}$ & $4.5+-\mathrm{NA}$ & $14+-\mathrm{NA}$ & $91+-\mathrm{NA}$ & $322160+-\mathrm{NA}$ & $27.1+-\mathrm{NA}$ & $86+-\mathrm{NA}$ & $91+-\mathrm{NA}$ \\
\hline Soil Nevada & USA & soil & 1 & soil & 454 & $\operatorname{mgm} 4451106.3$ & $1248623+-\mathrm{NA}$ & $725892+-\mathrm{NA}$ & $29880+-\mathrm{NA}$ & $2.4+-\mathrm{NA}$ & $8+-\mathrm{NA}$ & $84+-\mathrm{NA}$ & $326929+-\mathrm{NA}$ & $26.2+-\mathrm{NA}$ & $92+-\mathrm{NA}$ & $91+-\mathrm{NA}$ \\
\hline Plant soil USA & USA & soil & 1 & soil & HiSeq & $\operatorname{mgm} 4767414.3$ & $17632266+-\mathrm{NA}$ & $1425603+-\mathrm{NA}$ & $253827+-\mathrm{NA}$ & $1.4+-\mathrm{NA}$ & $15+-\mathrm{NA}$ & $33+-\mathrm{NA}$ & $1473019+-\mathrm{NA}$ & $8.4+-\mathrm{NA}$ & $85+-\mathrm{NA}$ & $52+-\mathrm{NA}$ \\
\hline Prairie Kansas & USA & prairie soil & 1 & soil & MiSeq & $\operatorname{mgm} 4477804.3$ & $5348832+-\mathrm{NA}$ & $349702+-\mathrm{NA}$ & $27412+-\mathrm{NA}$ & $0.5+-\mathrm{NA}$ & $9+-\mathrm{NA}$ & $51+-\mathrm{NA}$ & $270464+-\mathrm{NA}$ & $5.1+-\mathrm{NA}$ & $91+-\mathrm{NA}$ & $56+-\mathrm{NA}$ \\
\hline Soil PuertoRico & Puerto Rico & subtropical forest & 1 & soil & 454 & $\operatorname{mgm} 4446153.3$ & $725275+-\mathrm{NA}$ & $452063+-\mathrm{NA}$ & $10926+-\mathrm{NA}$ & $1.5+-\mathrm{NA}$ & $11+-\mathrm{NA}$ & $88+-\mathrm{NA}$ & $85868+-\mathrm{NA}$ & $11.8+-\mathrm{NA}$ & $89+-\mathrm{NA}$ & $95+-\mathrm{NA}$ \\
\hline Rhizosphere Amazonia & Brazil & $\begin{array}{l}\text { tropical broadleaf } \\
\text { forest }\end{array}$ & 1 & soil & HiSeq & $\operatorname{mgm} 4723911.3$ & $8884491+-\mathrm{NA}$ & $1415017+-\mathrm{NA}$ & $2075+-\mathrm{NA}$ & $\mathrm{O}+-\mathrm{NA}$ & $\mathrm{O}+-\mathrm{NA}$ & $52+-\mathrm{NA}$ & $1027815+-\mathrm{NA}$ & $11.6+-\mathrm{NA}$ & $100+-\mathrm{NA}$ & $60+-\mathrm{NA}$ \\
\hline Soil South-Africa & South-Africa & tropical grassland & 1 & soil & MiSeq & $\operatorname{mgm} 4819068.3$ & $2757834+-\mathrm{NA}$ & $759329+-\mathrm{NA}$ & $25123+-\mathrm{NA}$ & $0.9+-\mathrm{NA}$ & $6+-\mathrm{NA}$ & $64+-\mathrm{NA}$ & 414056 +- NA & $15+-\mathrm{NA}$ & $94+-\mathrm{NA}$ & $79+-\mathrm{NA}$ \\
\hline Shrubland California & USA & shrubland & 1 & soil & MiSeq & $\operatorname{mgm} 4806895.3$ & $2213724+-\mathrm{NA}$ & $47591+-\mathrm{NA}$ & $3742+-\mathrm{NA}$ & $0.2+-\mathrm{NA}$ & $1+-\mathrm{NA}$ & $11+-\mathrm{NA}$ & $249528+-\mathrm{NA}$ & $11+-\mathrm{NA}$ & $98+-\mathrm{NA}$ & $7+-\mathrm{NA}$ \\
\hline Shrubland Sudan & Sudan & shrubland & 1 & soil & MiSeq & $\operatorname{mgm} 4806896.3$ & $185966+-\mathrm{NA}$ & $1169+-\mathrm{NA}$ & $1181+-\mathrm{NA}$ & $0.6+-\mathrm{NA}$ & $18+-\mathrm{NA}$ & $7+-\mathrm{NA}$ & $5381+-\mathrm{NA}$ & $2.9+-\mathrm{NA}$ & $82+-\mathrm{NA}$ & $11+-\mathrm{NA}$ \\
\hline
\end{tabular}


Table S3. Functional richness and evenness averaged per site. Functional richness and evenness after rarefaction per site, based on the SEED functional

classes. For site including several samples, the mean and standard deviation have been calculated.

\begin{tabular}{|c|c|c|c|c|c|c|c|c|c|c|c|c|c|}
\hline & & All sequences & & & & Fungal seque & nces & & & Bacterial seq & uences & & \\
\hline Site & Ecosystem & $\begin{array}{l}\text { Number of annotated } \\
\text { sequences using } \\
\text { Diamond and } \\
\text { MEGAN6 }\end{array}$ & Rarefaction & $\begin{array}{l}\text { Functional } \\
\text { richness } \\
\text { after } \\
\text { rarefaction }\end{array}$ & $\begin{array}{l}\text { Functional } \\
\text { evenness after } \\
\text { rarefaction }\end{array}$ & $\begin{array}{l}\text { Number of } \\
\text { annotated } \\
\text { sequences } \\
\text { using } \\
\text { Diamond and } \\
\text { MEGAN6 }\end{array}$ & Rarefaction & $\begin{array}{l}\text { Functional } \\
\text { richness after } \\
\text { rarefaction }\end{array}$ & $\begin{array}{l}\text { Functional } \\
\text { evenness after } \\
\text { rarefaction }\end{array}$ & $\begin{array}{l}\text { Number of } \\
\text { annotated } \\
\text { sequences } \\
\text { using } \\
\text { Diamond and } \\
\text { MEGAN6 }\end{array}$ & Rarefaction & $\begin{array}{l}\text { Functional } \\
\text { richness after } \\
\text { rarefaction }\end{array}$ & $\begin{array}{l}\text { Functional evenness after } \\
\text { rarefaction }\end{array}$ \\
\hline air Amsterdam-Island (AMS & ) air & $3927+-3321$ & $1737+-456$ & $1087+-554$ & $0.94+-0.02$ & $81+-80$ & $81+-80$ & $66+-58$ & $0.99+-0.01$ & $554+-480$ & $360+-193$ & $270+-197$ & $0.96+-0.01$ \\
\hline air Beijing & air & $180196+-11408$ & $2000+-0$ & $4060+-112$ & $0.86+-0$ & $5960+-214$ & $500+-0$ & $1129+-92$ & $0.89+-0$ & $82004+-5643$ & $500+-0$ & $2835+-58$ & $0.87+-0$ \\
\hline air Cape-Point (CAP) & air & $8176+-4856$ & $2000+-0$ & $1634+-337$ & $0.93+-0.02$ & $211+-15$ & $211+-15$ & $162+-6$ & $0.97+-0$ & $1890+-726$ & $500+-0$ & $739+-192$ & $0.95+-0.01$ \\
\hline air Chacaltaya $(\mathrm{CHC})$ & air & $15853+-8907$ & $1848+-456$ & $2062+-714$ & $0.92+-0.02$ & $380+-219$ & $346+-175$ & $223+-109$ & $0.96+-0.02$ & $5268+-3052$ & $467+-99$ & $1142+-461$ & $0.93+-0.02$ \\
\hline air Grenoble (GRE) & air & $5765+-6870$ & $1802+-297$ & $1256+-700$ & $0.94+-0.02$ & $412+-382$ & $308+-156$ & $235+-153$ & $0.97+-0.01$ & $2193+-2949$ & $445+-86$ & $658+-528$ & $0.96+-0.02$ \\
\hline $\begin{array}{l}\text { air indoors New York } \\
\text { (indoors_NY) }\end{array}$ & air & $32135+-11235$ & $2000+-0$ & $3302+-299$ & $0.91+-0.01$ & $1546+-802$ & $500+-0$ & $697+-206$ & $0.95+-0.01$ & $10067+-4782$ & $500+-0$ & $2183+-387$ & $0.93+-0.01$ \\
\hline air Namco (NAM) & air & $23081+-19276$ & $2000+-0$ & $2280+-478$ & $0.91+-0.01$ & $596+-495$ & $381+-114$ & $287+-136$ & $0.95+-0.02$ & $7600+-6515$ & $500+-0$ & $1300+-372$ & $0.92+-0.02$ \\
\hline air New York (NY) & air & $5481+-4324$ & $1639+-561$ & $1384+-849$ & $0.89+-0.04$ & $286+-231$ & $275+-217$ & $150+-109$ & $0.91+-0.07$ & $769+-622$ & $362+-205$ & $446+-335$ & $0.94+-0.02$ \\
\hline air Puy-de-Dôme (PDD) & air & $11053+-9757$ & $1976+-75$ & $1700+-775$ & $0.93+-0.02$ & $656+-748$ & $300+-198$ & $297+-239$ & $0.96+-0.03$ & $4.277+-4138$ & $500+-0$ & $989+-617$ & $0.94+-0.03$ \\
\hline air Pic-du-Midi (PDM) & air & $9422+-8988$ & $1769+-490$ & $1575+-778$ & $0.94+-0.02$ & $363+-354$ & $267+-185$ & $218+-163$ & $0.98+-0.02$ & $3252+-3366$ & $460+-101$ & $832+-511$ & $0.95+-0.02$ \\
\hline air San Diego & air & $14573+-8176$ & $2000+-0$ & $2021+-81$ & $0.9+-0$ & $184+-191$ & $184+-191$ & $91+-66$ & $0.96+-0.04$ & $1737+-1841$ & $468+-46$ & $628+-429$ & $0.95+-0.01$ \\
\hline air Station-Nord (STN) & air & $2863+-2408$ & $1580+-594$ & $956+-547$ & $0.95+-0.02$ & $111+-111$ & $111+-111$ & $88+-81$ & $0.98+-0.01$ & $1089+-1085$ & $411+-127$ & $486+-400$ & $0.96+-0.01$ \\
\hline air Storm-Peak (STP) & air & $11763+-7684$ & $2000+-0$ & $1865+-519$ & $0.92+-0.01$ & $973+-537$ & $476+-58$ & $392+-131$ & $0.94+-0.02$ & $3757+-3006$ & $500+-0$ & $971+-409$ & $0.94+-0.02$ \\
\hline human feces Sydney & feces & $560641+-\mathrm{NA}$ & $2000+-\mathrm{NA}$ & $2802+-\mathrm{NA}$ & $0.82+-\mathrm{NA}$ & $3591+-\mathrm{NA}$ & $500+-\mathrm{NA}$ & $317+-\mathrm{NA}$ & $0.61+-\mathrm{NA}$ & $304338+-$ NA & $500+-\mathrm{NA}$ & $2557+-\mathrm{NA}$ & $0.87+-\mathrm{NA}$ \\
\hline leaf surface Israel & phyllosphere & $1042866+-\mathrm{NA}$ & $2000+-\mathrm{NA}$ & $4.292+-\mathrm{NA}$ & $0.87+-\mathrm{NA}$ & $10644+-$ NA & $500+-\mathrm{NA}$ & $1396+-\mathrm{NA}$ & $0.85+-\mathrm{NA}$ & $247373+-\mathrm{NA}$ & $500+-\mathrm{NA}$ & $3165+-\mathrm{NA}$ & $0.88+-\mathrm{NA}$ \\
\hline river water USA & river water & $295902+-\mathrm{NA}$ & $2000+-\mathrm{NA}$ & $3550+-\mathrm{NA}$ & $0.87+-\mathrm{NA}$ & $6142+-\mathrm{NA}$ & $500+-\mathrm{NA}$ & $1001+-\mathrm{NA}$ & $0.89+-\mathrm{NA}$ & $76857+-\mathrm{NA}$ & $500+-\mathrm{NA}$ & $2497+-\mathrm{NA}$ & $0.87+-\mathrm{NA}$ \\
\hline seawater Balearic sea & seawater & $340618+-\mathrm{NA}$ & $2000+-\mathrm{NA}$ & $2957+-\mathrm{NA}$ & $0.87+-\mathrm{NA}$ & $17554+-\mathrm{NA}$ & $500+-\mathrm{NA}$ & $1825+-\mathrm{NA}$ & $0.9+-\mathrm{NA}$ & $55185+-\mathrm{NA}$ & $500+-\mathrm{NA}$ & $1823+-\mathrm{NA}$ & $0.86+-\mathrm{NA}$ \\
\hline seawater Celtic sea & seawater & $335790+-\mathrm{NA}$ & $2000+-\mathrm{NA}$ & $3325+-\mathrm{NA}$ & $0.87+-\mathrm{NA}$ & $11736+-\mathrm{NA}$ & $500+-\mathrm{NA}$ & $1831+-\mathrm{NA}$ & $0.91+-\mathrm{NA}$ & $41271+-\mathrm{NA}$ & $500+-\mathrm{NA}$ & $1964+-\mathrm{NA}$ & $0.87+-\mathrm{NA}$ \\
\hline deep abyss USA & seawater & $333284+-\mathrm{NA}$ & $2000+-\mathrm{NA}$ & $3649+-\mathrm{NA}$ & $0.87+-\mathrm{NA}$ & $1006+-\mathrm{NA}$ & $500+-\mathrm{NA}$ & $390+-\mathrm{NA}$ & $0.92+-\mathrm{NA}$ & $43055+-\mathrm{NA}$ & $500+-\mathrm{NA}$ & $2590+-\mathrm{NA}$ & $0.9+-\mathrm{NA}$ \\
\hline $\begin{array}{l}\text { seawater Greenland sea } \\
\text { hydrothermal Vent Pacific }\end{array}$ & $\begin{array}{l}\text { seawater } \\
\text { hydrothermal }\end{array}$ & $417826+-\mathrm{NA}$ & $2000+-\mathrm{NA}$ & $3223+-\mathrm{NA}$ & $0.88+-\mathrm{NA}$ & $214.07+-\mathrm{NA}$ & $500+-\mathrm{NA}$ & $2164+-\mathrm{NA}$ & $0.91+-\mathrm{NA}$ & $97826+-\mathrm{NA}$ & $500+-\mathrm{NA}$ & $2376+-\mathrm{NA}$ & $0.87+-\mathrm{NA}$ \\
\hline Ocean & vent & $217796+-\mathrm{NA}$ & $2000+-\mathrm{NA}$ & $3621+-\mathrm{NA}$ & $0.87+-\mathrm{NA}$ & $3855+-\mathrm{NA}$ & $500+-\mathrm{NA}$ & $950+-\mathrm{NA}$ & $0.9+-\mathrm{NA}$ & $62974+-\mathrm{NA}$ & $500+-\mathrm{NA}$ & $2533+-\mathrm{NA}$ & $0.89+-\mathrm{NA}$ \\
\hline seawater Indian sea & seawater & $40507+-\mathrm{NA}$ & $2000+-\mathrm{NA}$ & $2178+-\mathrm{NA}$ & $0.9+-\mathrm{NA}$ & $799+-\mathrm{NA}$ & $500+-\mathrm{NA}$ & $476+-\mathrm{NA}$ & $0.96+-\mathrm{NA}$ & $12001+-\mathrm{NA}$ & $500+-\mathrm{NA}$ & $1183+-\mathrm{NA}$ & $0.93+-\mathrm{NA}$ \\
\hline seawater Irish sea & seawater & $287629+-\mathrm{NA}$ & $2000+-\mathrm{NA}$ & $3283+-\mathrm{NA}$ & $0.88+-\mathrm{NA}$ & $2394+-\mathrm{NA}$ & $500+-\mathrm{NA}$ & $662+-\mathrm{NA}$ & $0.89+-\mathrm{NA}$ & $32848+-\mathrm{NA}$ & $500+-\mathrm{NA}$ & $1843+-\mathrm{NA}$ & $0.86+-\mathrm{NA}$ \\
\hline
\end{tabular}




\begin{tabular}{|c|c|c|c|c|c|c|c|c|c|c|c|c|c|}
\hline seawater Mediterranean sea & seawater & $381180+-\mathrm{NA}$ & $2000+-\mathrm{NA}$ & $3375+-\mathrm{NA}$ & $0.87+-\mathrm{NA}$ & $3999+-\mathrm{NA}$ & $500+-\mathrm{NA}$ & $898+-\mathrm{NA}$ & $0.87+-\mathrm{NA}$ & $74727+-\mathrm{NA}$ & $500+-\mathrm{NA}$ & $2112+-\mathrm{NA}$ & $0.88+-\mathrm{NA}$ \\
\hline seawater North Atlantic & seawater & & & & & & & & & & & & \\
\hline Ocean & seawater & $206085+-\mathrm{NA}$ & $2000+-\mathrm{NA}$ & $3143+-\mathrm{NA}$ & $0.87+-\mathrm{NA}$ & $2956+-\mathrm{NA}$ & $500+-\mathrm{NA}$ & $771+-\mathrm{NA}$ & $0.9+-\mathrm{NA}$ & $35702+-\mathrm{NA}$ & $500+-\mathrm{NA}$ & $1663+-\mathrm{NA}$ & $0.89+-\mathrm{NA}$ \\
\hline sediments Peru & sediments & $6348+-1251$ & $2000+-0$ & $1138+-7$ & $0.92+-0$ & $13+-4$ & $13+-4$ & $13+-4$ & $1+-0$ & $133+-66$ & $133+-66$ & $90+-33$ & $0.97+-0.02$ \\
\hline sediments Pond & sediments & $10569+-5084$ & $2000+-0$ & $1791+-252$ & $0.92+-0.01$ & $647+-422$ & $441+-106$ & $367+-149$ & $0.97+-0.01$ & $7038+-5091$ & $500+-0$ & $1364+-392$ & $0.93+-0.01$ \\
\hline river sediments West & & & & & & & & & & & & & \\
\hline Virginia & sediments & $315551+-\mathrm{NA}$ & $2000+-\mathrm{NA}$ & $3869+-\mathrm{NA}$ & $0.87+-\mathrm{NA}$ & $10660+-\mathrm{NA}$ & $500+-\mathrm{NA}$ & $1223+-\mathrm{NA}$ & $0.88+-\mathrm{NA}$ & $74774+-\mathrm{NA}$ & $500+-\mathrm{NA}$ & $2381+-\mathrm{NA}$ & $0.88+-\mathrm{NA}$ \\
\hline snow Svalbard & snow & $26069+-15249$ & $2000+-0$ & $2243+-498$ & $0.91+-0.01$ & $648+-360$ & $418+-152$ & $329+-143$ & $0.96+-0.02$ & $8702+-4544$ & $500+-0$ & $1317+-356$ & $0.92+-0.02$ \\
\hline agricultural soil France & soil & $907295+-258019$ & $2000+-0$ & $764+-47$ & $0.72+-0.02$ & $8707+-6045$ & $442+-116$ & $129+-74$ & $0.68+-0.1$ & $7044+-2095$ & $500+-0$ & $118+-55$ & $0.49+-0.05$ \\
\hline soil Cote Saint Andre & soil & $34947+-16517$ & $2000+-0$ & $2552+-263$ & $0.9+-0.01$ & $783+-355$ & $491+-14$ & $350+-92$ & $0.94+-0.01$ & $8680+-3716$ & $500+-0$ & $1418+-191$ & $0.91+-0.01$ \\
\hline soil CraibStone & soil & $27629+-18784$ & $2000+-0$ & $2406+-327$ & $0.91+-0.01$ & $668+-473$ & $465+-46$ & $336+-127$ & $0.95+-0.02$ & $7980+-6183$ & $500+-0$ & $1346+-289$ & $0.92+-0.01$ \\
\hline cropland UK & soil & $122625+-44684$ & $2000+-0$ & $3490+-132$ & $0.87+-0$ & $5106+-1863$ & $500+-0$ & $1001+-112$ & $0.89+-0.02$ & $34986+-13329$ & $500+-0$ & $2254+-103$ & $0.89+-0.01$ \\
\hline forest soil Baltimore & soil & $606468+-\mathrm{NA}$ & $2000+-\mathrm{NA}$ & $3998+-\mathrm{NA}$ & $0.86+-\mathrm{NA}$ & $33130+-27346$ & $500+-0$ & $1438+-259$ & $0.84+-0.02$ & $\begin{array}{l}334568+- \\
288964\end{array}$ & $500+-0$ & $2518+-4$ & $0.86+-0$ \\
\hline soil Puerto Rico & soil & $170277+-\mathrm{NA}$ & $2000+-\mathrm{NA}$ & $3607+-\mathrm{NA}$ & $0.86+-\mathrm{NA}$ & $6380+-\mathrm{NA}$ & $500+-\mathrm{NA}$ & $971+-\mathrm{NA}$ & $0.88+-\mathrm{NA}$ & $45321+-\mathrm{NA}$ & $500+-\mathrm{NA}$ & $2229+-\mathrm{NA}$ & $0.87+-\mathrm{NA}$ \\
\hline grassland SA & soil & $191711+-271120$ & $1000+-1414$ & $2093+-2959$ & $0.43+-0.61$ & $14252+-9262$ & $500+-0$ & $1216+-199$ & $0.85+-0.01$ & $\begin{array}{l}305911+- \\
260034\end{array}$ & $500+-0$ & $3147+-93$ & $0.9+-0.02$ \\
\hline grassland USA & soil & $926515+-144620$ & $2000+-0$ & $3496+-45$ & $0.86+-0$ & $23892+-4.105$ & $500+-0$ & $1539+-35$ & $0.84+-0$ & $\begin{array}{l}242586+- \\
44860\end{array}$ & $500+-0$ & $2332+-42$ & $0.86+-0$ \\
\hline soil lucknow India & soil & $303263+-$ NA & $2000+-\mathrm{NA}$ & $3971+-\mathrm{NA}$ & $0.88+-\mathrm{NA}$ & $19077+-\mathrm{NA}$ & $500+-\mathrm{NA}$ & $1357+-\mathrm{NA}$ & $0.87+-\mathrm{NA}$ & $145062+-\mathrm{NA}$ & $500+-\mathrm{NA}$ & $2707+-\mathrm{NA}$ & $0.89+-\mathrm{NA}$ \\
\hline soil Nevada & soil & $305066+-\mathrm{NA}$ & $2000+-\mathrm{NA}$ & $3528+-\mathrm{NA}$ & $0.87+-\mathrm{NA}$ & $12931+-\mathrm{NA}$ & $500+-\mathrm{NA}$ & $1324+-\mathrm{NA}$ & $0.85+-\mathrm{NA}$ & $147232+-\mathrm{NA}$ & $500+-\mathrm{NA}$ & $2465+-\mathrm{NA}$ & $0.89+-\mathrm{NA}$ \\
\hline plant soil USA & soil & $1839508+-\mathrm{NA}$ & $2000+-\mathrm{NA}$ & $3610+-\mathrm{NA}$ & $0.87+-\mathrm{NA}$ & $65330+-\mathrm{NA}$ & $500+-\mathrm{NA}$ & $1663+-\mathrm{NA}$ & $0.84+-\mathrm{NA}$ & $612710+-\mathrm{NA}$ & $500+-\mathrm{NA}$ & $2491+-\mathrm{NA}$ & $0.87+-\mathrm{NA}$ \\
\hline prairie Kansas & soil & $475235+-\mathrm{NA}$ & $2000+-\mathrm{NA}$ & $3393+-\mathrm{NA}$ & $0.86+-\mathrm{NA}$ & $11087+-\mathrm{NA}$ & $500+-\mathrm{NA}$ & $1155+-\mathrm{NA}$ & $0.85+-\mathrm{NA}$ & $119659+-\mathrm{NA}$ & $500+-\mathrm{NA}$ & $2282+-\mathrm{NA}$ & $0.87+-\mathrm{NA}$ \\
\hline rhizosphere Amazonia & soil & $1061420+-\mathrm{NA}$ & $2000+-\mathrm{NA}$ & $3330+-\mathrm{NA}$ & $0.81+-\mathrm{NA}$ & $337+-\mathrm{NA}$ & $337+-\mathrm{NA}$ & $157+-\mathrm{NA}$ & $0.91+-\mathrm{NA}$ & $412216+-\mathrm{NA}$ & $500+-\mathrm{NA}$ & $1912+-\mathrm{NA}$ & $0.79+-\mathrm{NA}$ \\
\hline soil South-Africa & soil & $464748+-\mathrm{NA}$ & $2000+-\mathrm{NA}$ & $4239+-\mathrm{NA}$ & $0.88+-\mathrm{NA}$ & $8883+-\mathrm{NA}$ & $500+-\mathrm{NA}$ & $1092+-\mathrm{NA}$ & $0.85+-\mathrm{NA}$ & $187173+-\mathrm{NA}$ & $500+-\mathrm{NA}$ & $3252+-\mathrm{NA}$ & $0.91+-\mathrm{NA}$ \\
\hline shrubland California & soil & $65837+-\mathrm{NA}$ & $2000+-\mathrm{NA}$ & $2693+-\mathrm{NA}$ & $0.87+-\mathrm{NA}$ & $298+-\mathrm{NA}$ & $298+-\mathrm{NA}$ & $126+-\mathrm{NA}$ & $0.92+-\mathrm{NA}$ & $14541+-\mathrm{NA}$ & $500+-\mathrm{NA}$ & $1757+-\mathrm{NA}$ & $0.89+-\mathrm{NA}$ \\
\hline shrubland Sudan & soil & $1751+-\mathrm{NA}$ & $1751+-\mathrm{NA}$ & $864+-\mathrm{NA}$ & $0.96+-\mathrm{NA}$ & $77+-\mathrm{NA}$ & $77+-\mathrm{NA}$ & $68+-\mathrm{NA}$ & $0.99+-\mathrm{NA}$ & $727+-\mathrm{NA}$ & $500+-\mathrm{NA}$ & $437+-\mathrm{NA}$ & $0.97+-\mathrm{NA}$ \\
\hline
\end{tabular}


Table S4. Ratio between 16S and 18S rRNA gene copy numbers in air and soil. qPCR on the 16s rRNA gene and on the 18S rRNA gene on air and soil samples, and ratio between these qPCRs. Means and standard deviations were calculated on three (Cote Saint André), nine (Amsterdam-Island and Namco) and ten (Grenoble) samples. qPCR results for the air samples have already been presented in Tignat-Perrier et al., 2019.

qPCR 18S rRNA gene number qPCR 16S rRNA gene number

Ratio qPCR 16S/qPCR 18S

\section{AIR SAMPLES}

$\begin{array}{ll}\text { NAM (Namco) } & 4.97 \times 10^{3} \pm 3.44 \times 10^{3} \\ \text { GRE (Grenoble) } & 5.28 \times 10^{4} \pm 3.61 \times 10^{4}\end{array}$

$3.56 \times 10^{6} \pm 3.01 \times 10^{6} \quad 716$

AMS (Amsterdam-

Island)

$$
7.51 \times 10^{3} \pm 6.96 \times 10^{3}
$$

$1.20 \times 10^{6} \pm 9.38 \times 10^{5}$

\section{SOIL SAMPLES}

Côte Saint André 
Table S5. Dominant SEED functions in the metagenomes. Top 50 of the SEED functions observed in the air samples (mean $+/$ - standard deviation) considering

all the sequences (i.e. bacterial and fungal sequences).

\begin{tabular}{|c|c|c|c|c|c|c|c|c|c|c|c|c|c|}
\hline $\begin{array}{l}\text { Function } \\
\end{array}$ & air_AMS & air_Beijing & air_CAP & air_CHC & air_GRE & air_IndoorsNY & air_NAM & air_NY & air_PDD & air_PDM & air_SanDiego & air_STN & air_STP \\
\hline 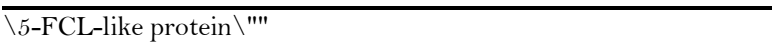 & $01+/-0.66$ & $2.04+/-0.12$ & $1.6+/-0.13$ & $1.9+/-0.13$ & $1.84+/-0.33$ & $1.62+/-0.08$ & $1.97+/-0.15$ & $1.53+/-0.54$ & $1.68+/-0.32$ & $1.78+/-0.37$ & $1.41+/-0.12$ & $1.47+/-0.24$ & $1.81+/-0.31$ \\
\hline$\backslash$ Long-chain-fatty-acid--CoA ligase (EC 6.2.1.3) \"" & $3+/-0.09$ & $1.35+/-0.3$ & $1.29+/-0.47$ & $1.46+/-0.25$ & $1.62+/-0.27$ & $1.17+/-0.2$ & $1.51+/-0.12$ & $1.12+/-0.53$ & $1.79+/-1.2$ & $1.58+/-0.22$ & $0.91+/-0.02$ & $2.01+/-0.45$ & $1.86+/-0.42$ \\
\hline$\backslash$ TonB-dependent receptor $\backslash " '$ & $1.3+/-0.44$ & $0.36+/-0.03$ & $1.02+/-0.4$ & $0.94+/-0.14$ & $1.07+/-0.46$ & $0.91+/-0.15$ & $0.98+/-0.12$ & $0.72+/-0.12$ & $0.99+/-0.51$ & $1.03+/-0.28$ & $0.45+/-0.04$ & $1.06+/-0.52$ & $0.83+/-0.27$ \\
\hline$\backslash 3$-oxoacyl-[acyl-carrier protein $]$ reductase (EC 1.1.1.100)\"' & $0.65+/-0.28$ & $0.55+/-0.02$ & $0.75+/-0.01$ & $0.9+/-0.11$ & $0.8+/-0.26$ & $0.62+/-0.06$ & $1.04+/-0.11$ & $0.56+/-0.17$ & $0.75+/-0.25$ & $0.79+/-0.24$ & $0.45+/-0.05$ & $0.84+/-0.09$ & $0.91+/-0.21$ \\
\hline$\backslash \mathrm{COG} 2363 \backslash " \prime$ & $0.53+/-0.3$ & $0.5+/-0.02$ & $0.58+/-0.14$ & $0.51+/-0.08$ & $0.58+/-0.16$ & $0.56+/-0.07$ & $0.49+/-0.11$ & $0.26+/-0.2$ & $0.54+/-0.13$ & $0.55+/-0.13$ & $0.56+/-0.26$ & $0.48+/-0.07$ & $0.45+/-0.05$ \\
\hline$\backslash$ Aldehyde dehydrogenase (EC 1.2.1.3) \"' & $0.43+/-0.21$ & $0.4+/-0.03$ & $0.44+/-0.1$ & $0.31+/-0.04$ & $0.58+/-0.13$ & $0.29+/-0.07$ & $0.39+/-0.06$ & $0.68+/-1.11$ & $0.42+/-0.2$ & $0.35+/-0.17$ & $0.29+/-0.04$ & $0.25+/-0.23$ & $0.47+/-0.09$ \\
\hline$\backslash$ Adenylate cyclase (EC 4.6.1.1) \"'" & $0.26+/-0.18$ & $0.17+/-0.02$ & $0.18+/-0.11$ & $0.36+/-0.15$ & $0.27+/-0.18$ & $0.29+/-0.06$ & $0.79+/-0.07$ & $0.25+/-0.24$ & $0.41+/-0.23$ & $0.46+/-0.14$ & $0.23+/-0.06$ & $0.53+/-0.02$ & $0.32+/-0.1$ \\
\hline$\backslash$ Beta-galactosidase (EC 3.2.1.23)\"' & $0.15+/-0.06$ & $0.23+/-0.05$ & $0.34+/-0.03$ & $0.34+/-0.15$ & $0.25+/-0.14$ & $0.22+/-0.05$ & $0.3+/-0.06$ & $1.41+/-2.13$ & $0.28+/-0.16$ & $0.3+/-0.21$ & $0.22+/-0.08$ & $0.18+/-0.25$ & $0.35+/-0.07$ \\
\hline$\backslash$ DNA-directed RNA polymerase beta' subunit (EC 2.7 .7 .6$) \backslash " '$ & $0.58+/-0.13$ & $0.53+/-0.03$ & $0.39+/-0.07$ & $0.38+/-0.07$ & $0.3+/-0.13$ & $0.15+/-0.04$ & $0.38+/-0.04$ & $0.09+/-0.08$ & $0.51+/-0.42$ & $0.39+/-0.11$ & $0.32+/-0.11$ & $0.29+/-0.17$ & $0.39+/-0.07$ \\
\hline$\backslash$ Aspartate aminotransferase (EC 2.6.1.1) \"' & $0.53+/-0.08$ & $0.39+/-0.02$ & $0.35+/-0.08$ & $0.38+/-0.07$ & $0.35+/-0.13$ & $0.43+/-0.07$ & $0.33+/-0.05$ & $0.4+/-0.32$ & $0.35+/-0.14$ & $0.34+/-0.09$ & $0.29+/-0.01$ & $0.37+/-0.28$ & $0.33+/-0.03$ \\
\hline$\backslash$ Cobalt-zinc-cadmium resistance protein CzcA \"'" & $0.17+/-0.1$ & $0.3+/-0.08$ & $0.2+/-0.01$ & $0.36+/-0.06$ & $0.26+/-0.13$ & $0.49+/-0.14$ & $0.26+/-0.04$ & $0.72+/-0.24$ & $0.4+/-0.18$ & $0.38+/-0.15$ & $0.24+/-0.01$ & $0.63+/-0.41$ & $0.22+/-0.04$ \\
\hline$\backslash$ DNA topoisomerase I (EC 5.99.1.2) \"'" & $0.07+/-0.07$ & $0.17+/-0.01$ & $0.08+/-0.05$ & $0.12+/-0.05$ & $0.08+/-0.03$ & $0.12+/-0.02$ & $0.16+/-0.04$ & $3.08+/-4.05$ & $0.14+/-0.11$ & $0.1+/-0.06$ & $0.16+/-0.01$ & $0.27+/-0.1$ & $0.1+/-0.03$ \\
\hline \High-affnity carbon uptake protein Hat/HatR \"' & $0.29+/-0.04$ & $0.16+/-0.09$ & $0.09+$ & $0.19+/-0.09$ & $1.27+/-0.94$ & -0.06 & $0.35+/-0.18$ & o. & 15 & $0.14+/-0.09$ & $0.08+/-0.04$ & $0.12+/-0.17$ & $0.32+/-0.19$ \\
\hline$\backslash$ Beta-lactamase $\backslash " '$ & $0.47+/-0.18$ & $0.15+/-0.01$ & $0.28+/-0.04$ & $0.29+/-0.12$ & $0.23+/-0.12$ & $0.26+/-0.06$ & $0.41+/-0.09$ & $0.62+/-$ & 0.1 & $0.41+/-0.11$ & $0.26+/-0$ & $0.2+/-0.16$ & $0.3+/-0.05$ \\
\hline$\backslash$ DNA-directed RNA polymerase beta subunit (EC 2.7 .7 .6$) \backslash " '$ & $0.39+/-0.19$ & $0.49+/-0.03$ & $0.35+/-0.1$ & $0.35+/-0.07$ & $0.24+/-0.11$ & $0.15+/-0.06$ & $0.34+/-0.09$ & $0.04+/-0.04$ & $0.44+/-0.48$ & $0.3+/-0.09$ & $0.31+/-0.12$ & $0.51+/-0.26$ & $0.3+/-0.04$ \\
\hline$\backslash$ Butyryl-CoA dehydrogenase (EC 1.3.99.2) \"' & $0.34+/-0.22$ & $0.29+/-0.04$ & $0.31+/-0.15$ & $0.3+/-0.13$ & $0.36+/-0.16$ & $0.19+/-0.05$ & $0.33+/-0.04$ & $0.21+/-0.1$ & $0.3+/-0.17$ & $0.3+/-0.09$ & $0.19+/-0.02$ & $0.36+/-0.23$ & $0.35+/-0.09$ \\
\hline$\backslash$ Aspartyl-tRNA(Asn) amidotransferase subunit A (EC 6.3.5.6)\"" & $0.16+/-0.15$ & $0.08+/-0$ & $0.04+/-0.06$ & $0.1+/-0.14$ & $0.04+/-0.05$ & $0.04+/-0.03$ & $0.06+/-0.03$ & $3.02+/-4.05$ & $0.04+/-0.03$ & $0.06+/-0.05$ & $0.11+/-0.02$ & $0.11+/-0.09$ & $0.07+/-0.03$ \\
\hline$\backslash$ FIG039061: hypothetical protein related to heme utilization $\backslash " '$ & $0.28+/-0.19$ & $0.34+/-0.02$ & $0.36+/-0.12$ & $0.29+/-0.12$ & $0.32+/-0.09$ & $0.33+/-0.06$ & $0.26+/-0.05$ & $0.17+/-0.14$ & $0.31+/-0.13$ & $0.3+/-0.11$ & $0.37+/-0.04$ & $0.2+/-0.09$ & $0.34+/-0.07$ \\
\hline$\backslash$ DNA polymerase III alpha subunit (EC 2.7 .7 .7$) \backslash " "$ & $0.32+/-0.11$ & $0.39+/-0$ & $0.47+/-0.15$ & $0.34+/-0.06$ & $0.27+/-0.13$ & $0.24+/-0.02$ & $0.36+/-0.03$ & $0.11+/-0.09$ & $0.27+/-0.09$ & $0.32+/-0.2$ & $0.29+/-0.06$ & $0.17+/-0.12$ & $0.24+/-0.09$ \\
\hline$\backslash$ D-3-phosphoglycerate dehydrogenase (EC 1.1.1.95) \"'" & $0.48+/-0.09$ & $0.26+/-0$ & $0.27+/-0.06$ & $0.29+/-0.08$ & $0.3+/-0.13$ & $0.29+/-0.02$ & $0.3+/-0.06$ & $0.1+/-0.08$ & $0.29+/-0.12$ & $0.3+/-0.12$ & $0.27+/-0.14$ & $0.49+/-0.41$ & $0.25+/-0.08$ \\
\hline \3-ketoacyl-CoA thiolase (EC 2.3.1.16) \"' & $0.43+/-0.06$ & $0.41+/-0.03$ & $0.24+/-0.1$ & $0.28+/-0.04$ & $0.31+/-0.17$ & $0.19+/-0.02$ & $0.3+/-0.04$ & $0.16+/-0.1$ & $0.25+/-0.11$ & $0.29+/-0.14$ & $0.23+/-0.12$ & $0.37+/-0.16$ & $0.34+/-0.1$ \\
\hline$\backslash$ Arylsulfatase (EC 3.1.6.1) \"' & $0.61+/-0.09$ & $0.11+/-0.03$ & $1.17+/-0.93$ & $0.17+/-0.03$ & $0.16+/-0.09$ & $0.08+/-0.02$ & $0.28+/-0.09$ & $0.09+/-0.05$ & $0.15+/-0.11$ & $0.19+/-0.11$ & $2.98+/-0.08$ & $0.2+/-0.09$ & $0.12+/-0.05$ \\
\hline$\backslash$ Enoyl-CoA hydratase (EC 4.2.1.17) \"' & $0.31+/-0.1$ & $0.24+/-0$ & $0.24+/-0.05$ & $0.31+/-0.12$ & $0.27+/-0.11$ & $0.26+/-0.07$ & $0.34+/-0.07$ & $0.16+/-0.06$ & $0.24+/-0.06$ & $0.3+/-0.11$ & $0.21+/-0.04$ & $0.46+/-0.04$ & $0.27+/-0.04$ \\
\hline$\backslash$ Acetyl-coenzyme A synthetase (EC 6.2.1.1) \"" & $0.15+/-0.07$ & $0.38+/-0.01$ & $0.36+/-0.21$ & $0.35+/-0.09$ & $0.29+/-0.09$ & $0.21+/-0.04$ & $0.27+/-0.04$ & $0.27+/-0.16$ & $0.24+/-0.11$ & $0.28+/-0.07$ & $0.2+/-0.12$ & $0.23+/-0.04$ & $0.31+/-0.03$ \\
\hline$\backslash$ Copper-translocating P-type ATPase (EC 3.6.3.4) \"' & $0.12+/-0.05$ & $0.35+/-0.05$ & $0.18+/-0.04$ & $0.2+/-0.09$ & $0.24+/-0.17$ & $0.62+/-0.21$ & $0.15+/-0.04$ & $0.7+/-0.23$ & $0.28+/-0.18$ & $0.23+/-0.14$ & $0.19+/-0.14$ & $0.29+/-0.17$ & $0.17+/-0.08$ \\
\hline \multicolumn{14}{|l|}{$\backslash$ diguanylate cyclase/phosphodiesterase (GGDEF \& EAL domains) with } \\
\hline PAS/PAC sensor(s)\"" & $0.11+/-0.14$ & $0.14+/-0.01$ & $0.12+/-0.07$ & $0.25+/-0.08$ & $0.24+/-0.14$ & $0.26+/-0.02$ & $0.38+/-0.06$ & $0.13+/-0.08$ & $0.3+/-0.18$ & $0.33+/-0.14$ & $0.16+/-0.08$ & $0.5+/-0.1$ & $0.28+/-0.08$ \\
\hline$\backslash$ Chaperone protein DnaK $\backslash " "$ & $0.29+/-0.2$ & $0.34+/-0.05$ & $0.26+/-0.06$ & $0.24+/-0.06$ & $0.3+/-0.17$ & $0.17+/-0.03$ & $0.28+/-0.03$ & $0.16+/-0.1$ & $0.3+/-0.14$ & $0.29+/-0.12$ & $0.29+/-0.09$ & $0.37+/-0.21$ & $0.23+/-0.03$ \\
\hline
\end{tabular}


〈UDP-glucose 4-epimerase (EC 5.1.3.2) \"'

$\backslash$ Excinuclease $\mathrm{ABC}$ subunit $\mathrm{A} \backslash " \mathrm{\prime \prime}$

$\backslash$ Aconitate hydratase (EC 4.2.1.3) \"'

$\backslash$ Transcription-repair coupling factor $\backslash " '$

$\backslash$ Acriflavin resistance protein $\backslash "$ "

$\backslash$ Alcohol dehydrogenase (EC 1.1.1.1) \"'

$\backslash$ Malonyl CoA-acyl carrier protein transacylase (EC 2.3.1.39)\"'

$\backslash$ Glutamate synthase [NADPH] large chain (EC 1.4.1.13)\"'

Carbamoyl-phosphate synthase large chain (EC 6.3.5.5)\"'

$\backslash$ Heat shock protein 60 family chaperone GroEL $\backslash "$ "

Thioredoxin reductase (EC 1.8.1.9)\"'

$\backslash$ ClpB protein $\backslash "$

$\backslash$ DNA gyrase subunit A (EC 5.99.1.3) \""

$\backslash$ Multimodular transpeptidase-transglycosylase (EC 2.4.1.129) (EC 3.4.-.-

)$\backslash "$

Alkaline phosphatase (EC 3.1.3.1)\"'

$\backslash$ Asparagine synthetase [glutamine-hydrolyzing] (EC 6.3.5.4)\"'"

$\backslash$ Translation elongation factor $\mathrm{G} \backslash$ "'”

$\checkmark 5$-methyltetrahydrofolate--homocysteine methyltransferase

2.1.1.13)\"'

$\backslash$ Threonine dehydrogenase and related Zn-dependent dehydrogenases $\backslash$ " $\backslash$ Succinate dehydrogenase flavoprotein subunit (EC 1.3.99.1)〉""

$\backslash$ DNA polymerase I (EC 2.7.7.7)\"'

$\backslash$ Catalase (EC 1.11.1.6) \"'"

$\backslash$ Type I restriction-modification system, restriction subunit R (EC $3.1 .21 .3) \backslash " \prime$ EC

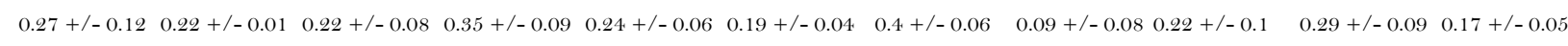

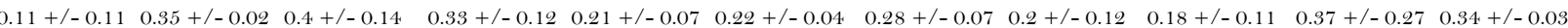

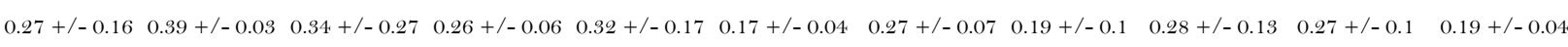
$\begin{array}{lllllllllllll}0.11+/-0.14 & 0.33+/-0.01 & 0.29+/-0.12 & 0.27+/-0.05 & 0.13+/-0.11 & 0.22+/-0.08 & 0.22+/-0.05 & 0.64+/-0.94 & 0.26+/-0.09 & 0.25+/-0.08 & 0.18+/-0.12\end{array}$ $0.32+/-0.17 \quad 0.16+/-0 \quad 0.41+/-0.010 .26+/-0.1 \quad 0.16+/-0.090 .32+/-0.12 \quad 0.23+/-0.060 .23+/-0.120 .2+/ / 0.11 \quad 0.31+/-0.080 .5+/-0.05$

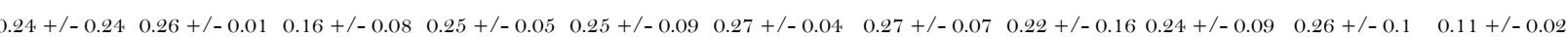
$0.53+/-0.11 \quad 0.16+/-0.010 .28+/-0.14 \quad 0.22+/-0.11 \quad 0.36+/-0.17 \quad 0.15+/-0.05 \quad 0.25+/-0.06 \quad 0.19+/-0.120 .2+/-0.08 \quad 0.21+/-0.110 .22+/-0.04$

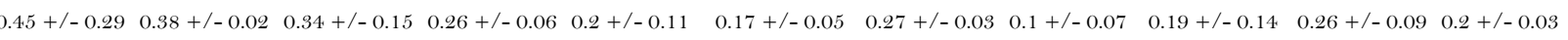
$\begin{array}{llllllllllll}0.14+/-0.06 & 0.38+/-0 & 0.24+/-0.09 & 0.25+/-0.07 & 0.2+/-0.05 & 0.16+/-0.03 & 0.24+/-0.04 & 0.12+/-0.07 & 0.27+/-0.28 & 0.31+/-0.17 & 0.26+/-0.08\end{array}$ $0.2+/-0.06 \quad 0.34+/-0 \quad 0.48+/-0.5 \quad 0.28+/-0.08 \quad 0.2+/-0.13 \quad 0.14+/-0.01 \quad 0.28+/-0.04 \quad 0.08+/-0.07 \quad 0.26+/-0.09 \quad 0.23+/-0.110 .48+/-0.04$ $0.2+/-0.19 \quad 0.94+/-0.01 \quad 0.22+/-0.11 \quad 0.3+/-0.08 \quad 0.18+/-0.11 \quad 0.2+/-0.02 \quad 0.29+/-0.090 .16+/-0.080 .26+/-0.07 \quad 0.24+/-0.1 \quad 0.11+/-0.09$

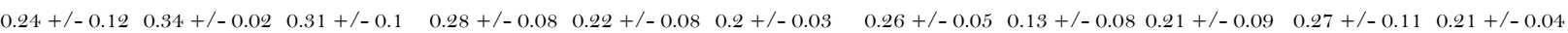

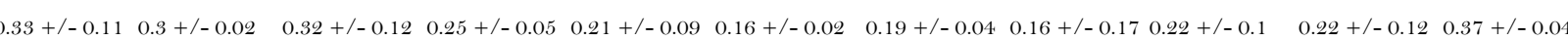

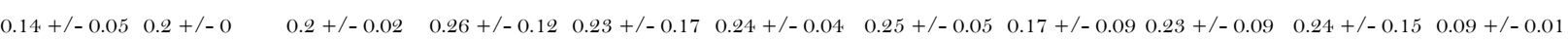

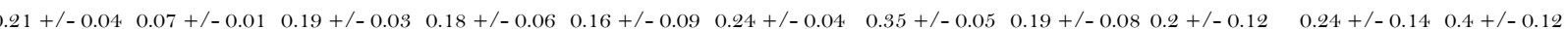
$0.12+/-0.14 \quad 0.12+/-0 \quad 0.13+/-0.02 \quad 0.15+/-0.08 \quad 0.31+/-0.21 \quad 0.13+/-0.03 \quad 0.17+/-0.06 \quad 0.16+/-0.110 .25+/-0.12 \quad 0.29+/-0.2 \quad 0.07+/-0$ $0.24+/-0.170 .35+/-0.03 \quad 0.24+/-0.11 \quad 0.25+/-0.110 .92+/-0.050 .11+/-0.04 \quad 0.29+/-0.040 .08+/-0.060 .25+/-0.21 \quad 0.24+/-0.160 .93+/-0.08$

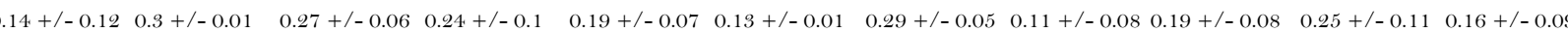

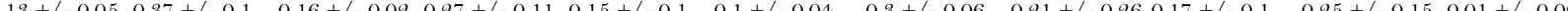
$0.25+/-0.020 .29+/-0.01 \quad 0.21+/-0.02 \quad 0.18+/-0.08 \quad 0.19+/-0.1 \quad 0.14+/-0.07 \quad 0.25+/-0.04 \quad 0.15+/-0.1 \quad 0.18+/-0.07 \quad 0.23+/-0.120 .24+/-0.04$ $\begin{array}{lllllllllll}14+/-0.03 & 0.2+/-0.01 & 0.4+/-0.03 & 0.22+/-0.05 & 0.18+/-0.13 & 0.21+/-0.02 & 0.24+/-0.06 & 0.13+/-0.11 & 0.19+/-0.04 & 0.22+/-0.15 & 0.19+/-0.01\end{array}$

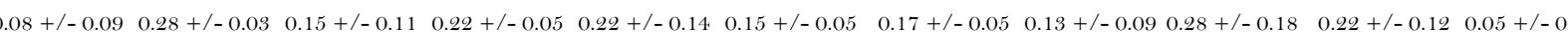

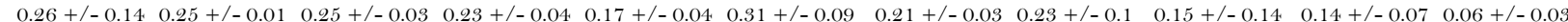

$0.41+/-0.15 \quad 0.23+/-0.12$ $0.2+/-0.03 \quad 0.2+/-0.05$ $0.09+/-0.120 .26+/-0.09$ $0.23+/-0.17 \quad 0.25+/-0.06$ $0.33+/-0.150 .2+/-0.1$ $0.16+/-0.110 .31+/-0.05$ $0.2+/-0.03 \quad 0.3+/-0.07$ $0.28+/-0.160 .24+/-0.05$ $0.28+/-0.16 \quad 0.17+/-0.1$ $0.15+/-0.220 .2+/-0.08$ $0.18+/-0.02 \quad 0.24+/-0.03$ $0.13+/-0.190 .17+/-0.09$ $0.3+/-0.06 \quad 0.2+/-0.04$

$0.18+/-0.020 .23+/-0.08$ $0.29+/-0.2 \quad 0.18+/-0.08$ $0.29+/-0.070 .31+/-0.17$ $0.21+/-0.29 \quad 0.2+/-0.05$ $0.27+/-0.02 \quad 0.2+/-0.12$ $0.07+/-0.09 \quad 0.29+/-0.09$ $0.23+/-0.04 \quad 0.22+/-0.08$ $0.2+/-0.03 \quad 0.17+/-0.09$ $0.05+/-0.080 .21+/-0.06$ 
2 Tignat-Perrier, R., Dommergue, A., Thollot, A., Keuschnig, C., Magand, O., Vogel, T. M. and 3 Larose, C.: Global airborne microbial communities controlled by surrounding landscapes and wind 4 conditions, Sci Rep, 9(1), 1-11, doi:10.1038/s41598-019-51073-4, 2019. 